\title{
EFFECT OF INTRALESIONAL INJECTION OF TRIAMCINOLONE ACETONIDE ON KELOID- A PROSPECTIVE OBSERVATIONAL STUDY
}

\author{
Radharaman Panda ${ }^{1}$
}

${ }^{1}$ Former Assistant Professor, Department of General Surgery, Late Sri Lakhiram Agarwal Memorial Government Medical College.

\section{ABSTRACT}

\section{BACKGROUND}

Wound repairs normally culminate in fine scars, the only evidence of dermal injuries. In certain individuals; however, the repair process may go awry and wound may heal with large elevated scar known as Keloid or hypertrophic scar. Many treatment methods are available. All have merits and demerits, but till now initial treatment for keloid is intralesional injection of Triamcinolone Acetonide (TA).

The aim of this study is to find out the different local effects of intralesional injection of Triamcinolone Acetonide (TA) on keloid.

\section{MATERIALS AND METHODS}

An analytical observational prospective study was conducted on 156 patients of keloid on different sites of body, they were treated with intralesional injection of TA. All patients were kept on followup. Clinical data and final results of all patients were analysed and reported.

\section{RESULTS}

Out of 156 patients, 92 were female and 64 were male; 12 patients between 5 - 10 years, 44 patients between 11-20 years, 68 patients between 21-30 years, 16 patients between 31-40 years, 8 patients between $41-50$ years and 8 patients between 51-60 years. Effect of TA on keloid were documented as $43.59 \%$ recurrence, atrophy of skin in $17.95 \%$, ulcer $10.26 \%$, abscess $5.13 \%$, vascular dilatation $8 \%$ and hypopigmentation of skin $15.38 \%$.

\section{CONCLUSION}

Different effects are observed in keloid patients treated with TA but till now intralesional injection of TA is the initial treatment of choice. The treatment depends on acceptation and economy of treatment.

\section{KEYWORDS}

Intralesional, Injection, Triamcinolone Acetonide, Keloid.

HOW TO CITE THIS ARTICLE: Panda R. Effect of intralesional injection of triamcinolone acetonide on keloid- A prospective observational study. J. Evolution Med. Dent. Sci. 2017;6(74):5303-5307, DOI: 10.14260/Jemds/2017/1151

\section{BACKGROUND}

Biochemical process of wound repair normally culminates in fine scars, the only evidence of dermal injury. In certain individuals; however, the repair process may go awry and wound may heal with large elevated scar known as Keloid or hypertrophic scar. Exact aetiology of formation of keloid isn't properly understood. Complications of abnormal scar formation are often severe. Many modalities of treatment are available for keloid. They include corticosteroid intralesional

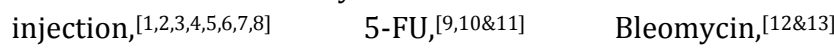
Verapamil,[14,15,16,17,18,19] Silicone gel sheet,[20.21,22,23] laser therapy, ${ }^{[24]}$ cryotherapy,[25,26,27] interferon,[28] Radiation,[29,30] Asiaticoside.[31] But till now no absolute result oriented treatment method has been found. Intralesional injection of Triamcinolone Acetonide alone has been used since long and till now has retained its efficacy as an initial treatment of keloid initially.

Financial or Other, Competing Interest: None.

Submission 07-08-2017, Peer Review 31-08-2017,

Acceptance 06-09-2017, Published 14-09-2017.

Corresponding Author:

Dr. Radharaman Panda,

Former Assistant Professor,

Department of General Surgery,

Late Sri Lakhiram Agarwal Memorial

Government Medical College.

E-mail: drradharaman@yahoo.co.in

DOI: $10.14260 /$ jemds $/ 2017 / 1151$
Study was conducted on 156 patients with keloid of age about 5 years and above. Out of these, chest keloids were 53.85\% (Fig. 1), 15.38\% upper limb (Fig. 2), 7.69\% lower limb (Fig. 3), 20.51\% ear (Fig. 4) and 2.56\% face (Fig. 5). In all the keloid patients, intralesional injection of Triamcinolone Acetonide (TA) was given. The patients were kept under keen observation and regular followups. It was found that, out of 156 patients, $17.95 \%$ atrophy of skin (Fig. 6), 15.38\% hypopigmentation (Fig. 7), 8.0\% vascular dilatation (Fig. 8), 10.26\% ulceration (Fig. 9). 5.13\% keloid abscess (Fig. 10) and $43.59 \%$ recurrence. (Fig. 11).

\section{MATERIALS AND METHODS}

This analytical observational prospective study was carried out in the Department of General Surgery at Late Sri Lakhiram Agarwal Memorial Medical College which is a tertiary care referral teaching hospital. Consecutive cases with keloid were included by the author irrespective of the aetiology. In between Nov. 2014 to Oct. 2016, 156 patients attended the Dept. of Surgery, All these patients presented with swelling in different sites of body. Each patient's history was taken, examined properly and evaluated. Medical diseases like Diabetes mellitus, hypertension, tuberculosis and any auto immune disease were excluded. In doubtful cases, incisional biopsy was done for diagnosis. All 156 patients were free of medical diseases. Patients were categorised as per sex, age and different sites of occurrence of keloid. All 156 cases were selected and planned for intralesional injection of TA. Proper 
written consent was taken from the patients for intralesional injection, and counselled about the disease and side effects of drug.

All selected patients were clinically assessed and the dimensions of the keloid [length, breath and height] were measured from skin surface by calliper. Consent for Photograph of disease site of all patients was taken before and during followup period of intralesional injection.

Intrakeloidal injection was given by a sterile insulin syringe loaded with TA with concentration of $40 \mathrm{mg} / \mathrm{mL}$ of injection. Preferred position of patient was supine because if severe pain occurred during injection, patient will feel discomfort and symptoms of vasovagal attack may occur. The injection site (keloid) prepared with alcoholic preparation of povidone iodine solution (5\%). Dose of injection was given as per size of keloid. Maximum dose of injection was restricted to $120 \mathrm{mg}$ per sitting. Interval of injection was between 4-6 weeks till complete regression of swelling. The patients were followed up regularly. If the patient didn't come in time, the patient was called by telephone for followup. During the followup period, the regression of size of keloid was assessed clinically and also by the feedback provided by the patient. During the treatment period, the local effect of injection like ulcer, abscess, hypopigmentation, dermal atrophy, local vasodilatation and recurrence of disease was observed.

\section{RESULTS}

156 patients with keloid attending the Department of Surgery of a tertiary teaching hospital attached to Lakhiram Agarwal Memorial Govt, Medical College, Raigarh (CG) were included in the present study. The study period was from November 2014 to December 2016. All patients complained of itching of the swelling irrespective of duration of disease. Some patients had severe itching of keloid causing abrasion of surrounding skin. Itching relieved dramatically within 7 days of first dose of intralesional injection of TA. Initial injection of TA to the keloidal tissue is very laborious due to its firm consistency. Subsequent injections are a bit easy to administer due to decreased tissue compactness.

In this study, it was found that, out of the total no. of patients (n-156), male population was $41.03 \%(n-64)$ and female population was $58.97 \%$ (n-92). Male to female ratio was 1: 1.1473. Keloid patients in different age group were: 510 years (n-12) 7.69\%, 11-20 years (44) 28.21\%, 21-30 years (n-68) 43.59\%, 31-40 years (n-16) 10.26\%, 41-50 years (n-8) $5.13 \%$ and $51-60$ years (n-8) $5.13 \%$ (Table 1). Irrespective of age group, different sites of distribution was $53.85 \%$ on chest, ear $20.51 \%$, face $2.56 \%$, upper limb $15.38 \%$ and lower limb $7.69 \%$ (Table. 2). Local effects of TA on keloid were- severe pain during injection $76.92 \%$, atrophy of skin $17.95 \%$, ulcer $10.26 \%$, abscess $5.13 \%$, vascular dilatation $8 \%$, hypopigmentation of skin $15.38 \%$, and recurrence $43.59 \%$ (Table. 3).

Recurrence was high in female with long duration of Keloid on chest (between two breasts). Probably, it may be due to stretching of area by both breasts. It was observed that maximum recurrence occurred of keloid on chest with length more than $2.5 \mathrm{~cm}$. Recurrence of keloid of lower limb was less as compared to other region of body. Hypopigmentation of skin after intralesional injection of TA was mostly found on upper and lower limb. Vascular dilatation was noticed usually on keloid of chest and ear.

\begin{tabular}{|c|c|c|}
\hline Age Group (In years) & No. of Patients (n) & Percentage (\%) \\
\hline $5-10$ & 12 & 7.69 \\
\hline $11-20$ & 44 & 28.21 \\
\hline $21-30$ & 68 & 43.59 \\
\hline $31-40$ & 16 & 10.26 \\
\hline $41-50$ & 08 & 05.13 \\
\hline $50-60$ & 08 & 05.13 \\
\hline \multicolumn{2}{|c|}{ Table 1. Occurrence of Keloid (\% age) } \\
in Different Age Groups \\
\hline
\end{tabular}

\begin{tabular}{|c|c|c|}
\hline Site & No. of Patients (n) & Percentage (\%) \\
\hline Chest & 84 & 53.85 \\
\hline Ear & 32 & 20.51 \\
\hline Face & 04 & 02.56 \\
\hline Upper limb & 24 & 15.38 \\
\hline Lower limb & 12 & 07.69 \\
\hline \multicolumn{2}{|c|}{ Table 2. Different Sites of Distribution of Keloid } \\
\hline
\end{tabular}

\begin{tabular}{|c|c|c|}
\hline Effect of TA Injection & $\begin{array}{l}\text { No. of Patients } \\
\text { (n) }\end{array}$ & Percentage (\%) \\
\hline Skin Atrophy & 28 & 17.95 \\
\hline Ulcer & 16 & 10.26 \\
\hline Keloid abscess & 08 & 05.13 \\
\hline Vascular dilation & 12 & 08.00 \\
\hline Hypopigmentation & 24 & 15.38 \\
\hline Recurrence & 68 & 43.59 \\
\hline \multicolumn{3}{|c|}{$\begin{array}{l}\text { Table 3. Local Effect of Intralesional Injection of } \\
\text { Triamcinolone Acetonide (TA) }\end{array}$} \\
\hline
\end{tabular}

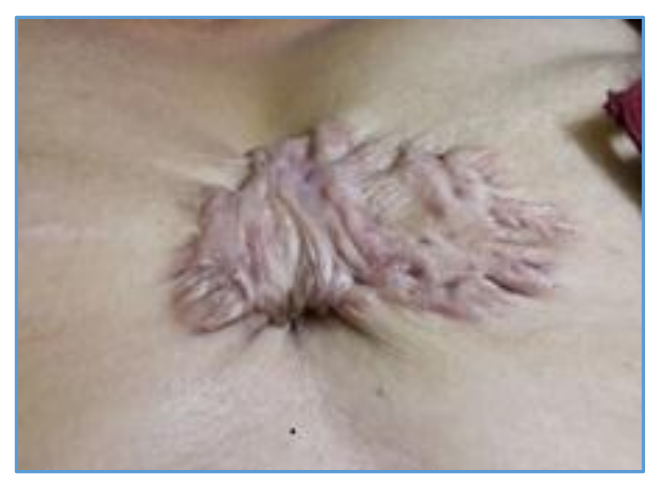

Figure 1. Keloid on the Chest of an Adult Female in between Breasts

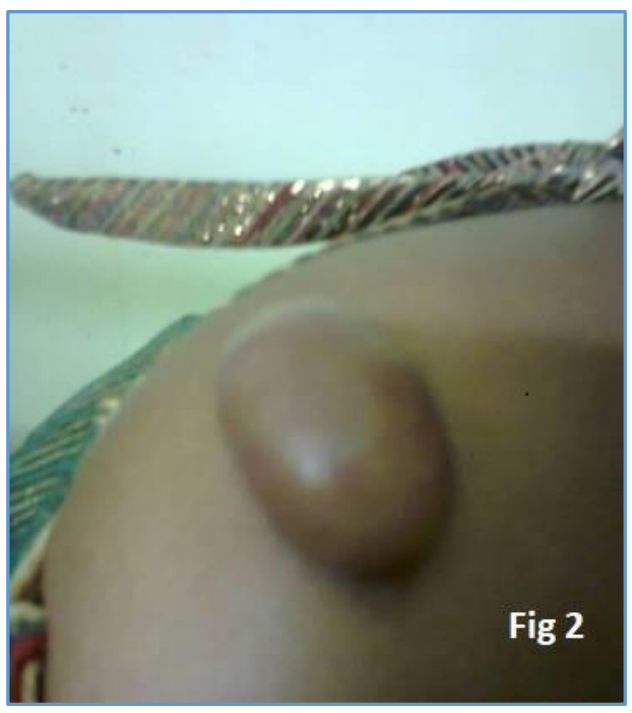

Figure 2. Keloid on the Right Shoulder of a 12-year-old Female Child 


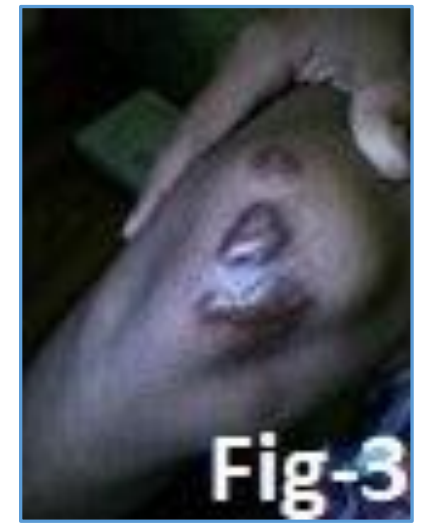

Figure 3. Keloid on the Right Knee of a 14-year-old Child

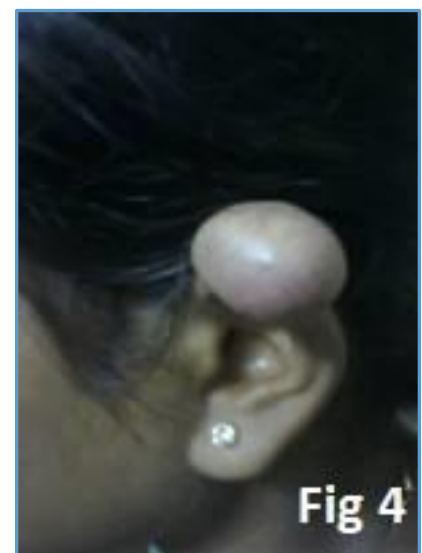

Figure 4. Keloid on Ear of an Adult Female

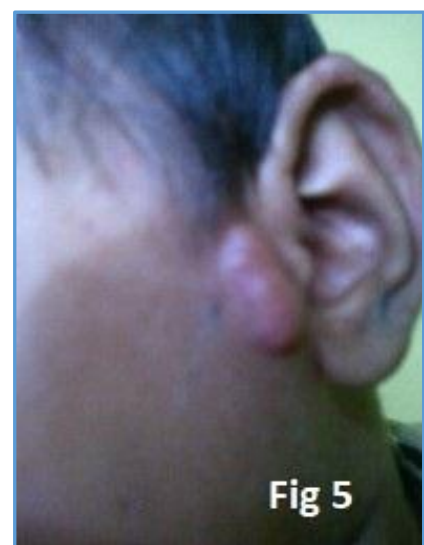

Figure 5. Keloid on the Face in Front of Tragus of Ear of a 10-year-old Male Child

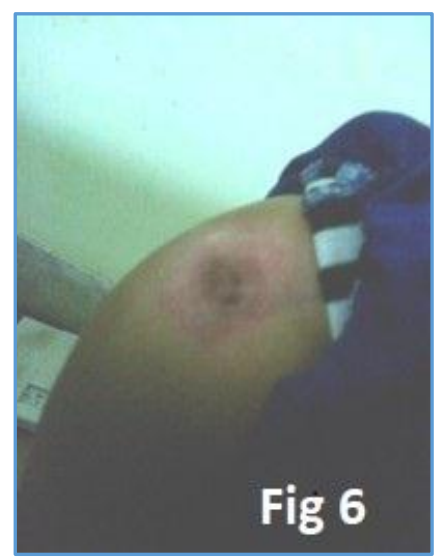

Figure 6. Atrophy of skin on the Shoulder of a 12-year-old Female Child

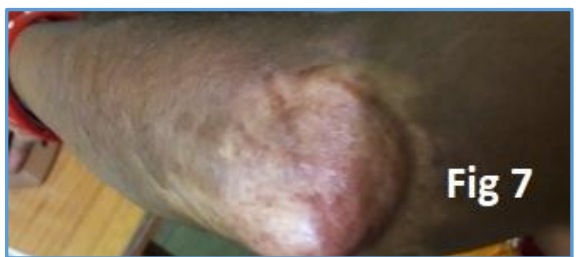

Figure 7. Hypopigmentation of Skin of Elbow Keloid of an Adult Female following TA Injection

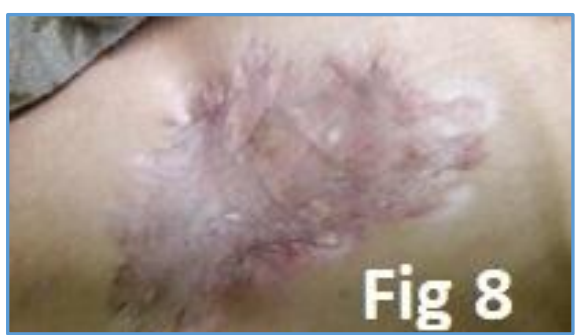

Figure 8. Local Vascular Dilation on Injected Site of Chest Keloid

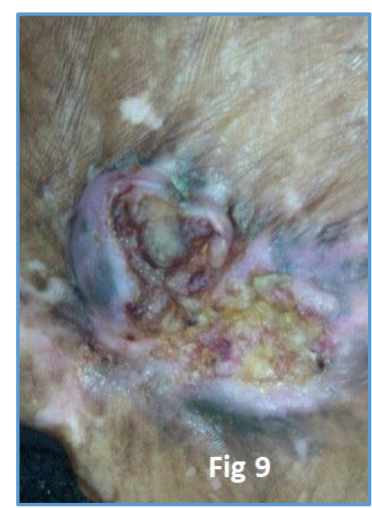

Figure 9. Ulcer on Chest Keloid of an Adult Male

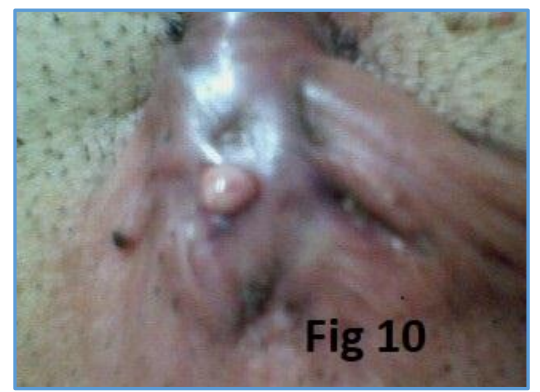

Figure 10. Keloid Abscess on the Chest of a 55-year-old Male, Pus is Coming Out

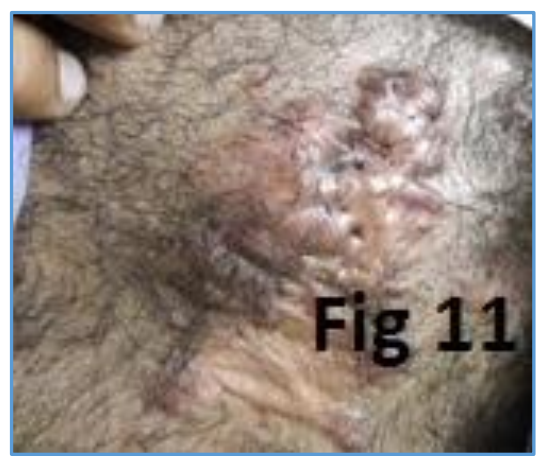

Figure 11. Recurrence of Keloid on the Chest of a Male Patient 


\section{DISCUSSION}

Complications of abnormal scar formation are often severe and their clinical management is frustrating. Both surgeon and patient must accept the reality that neither pharmacological intervention nor technical skill will ensure prevention or cure. Different modalities of treatment are available for keloid and many research studies were done, but till now the initial approach to treat keloid is intralesional injection of Steroid. Triamcinolone Acetonide is the steroid of choice. It inhibits prolylhydroxylase activity. It increases collagenolytic activity. It alters various aspect of the inflammatory response, which is the major modulator of the healing process.

All patients accepted intralesional TA injection easily as the initial choice of treatment.

\section{In this Study, it was Noticed that-}

1. Maximum occurrence of keloid was in age group between 21-30 years and very less percentage found in 50 years \& above.

2. Highest site of Keloid was on chest (sternal area) and very low percentage on face.

3. Local effect of TA on keloid - maximum percentage of patients presented with severe pain, the cause may be due to increase in volume and stretching of keloid which decreased on subsequent injection. Due to severe pain some patients felt discomfort, severe sweating and vasomotor collapse. In these cases, patients were resuscitated and recovered to normal. A very few patients developed abscess.

4. Percentage of recurrence of keloid was high within 3 months of completion of therapy.

\section{CONCLUSION}

Keloid is a sequence of abnormal healing process of wound. There is no exact defined aetiology for keloid formation. Different modalities of treatment are given to patients leading to different results.

Benefits of TA on keloid was its high rate of acceptance and its low cost. So, intralesional injection of TA is initial treatment of choice. If there is failure, then alternate treatment modalities are started.

In this study, after weighing the benefits and adverse effects of intralesional TA injection, it can be concluded that this mode of treatment is better as an initial therapy.

\section{REFERENCES}

[1] El-Hefnawi H. Treatment of keloid with Asiaticoside. Dermatologica 1962;125:387-92.

[2] Murray RD. Kenalog and the treatment of hypertrophied scars and keloids in Negroes and whites. Plast Reconstr Surg 1963;31:275-80.

[3] Montgomery RM, Portnoy M. Triamcinolone acetonide injected sublesionally in the treatment of dermatoses. J Am Geriatr Soc 1963:1104-7.

[4] Abdel-Fattah AM. Unusual complications of triamcinolone injected keloids: tissue necrosis and systemic corticosteroid effects. Br J Plast Surg 1976;29(4):283.

[5] Iudenich VV, Grishkevich VM, Iudenich AA. Triamcinolone acetonide in the treatment of hypertrophic and keloid scars. Sov Med 1985;2:26-9.
[6] Muneuchi G, Suzuki S, Onodera M, et al. Long-term outcome of intralesional injection of triamcinolone acetonide for the treatment of keloid scars in Asian patients. Scand J Plast Reconstr Surg Hand Surg 2006;40(2):111-6.

[7] Wong TS, Li JZ, Chen S, et al. The efficacy of triamcinolone acetonide in keloid treatment: a systematic review and meta-analysis. Front Med (Lausanne) 2016;3:71.

[8] Koh WL, Lim SP. Dramatic hyperpigmentation of keloids after intralesional triamcinolone acetonide injection. Dermatol Online J 2015;21(5).

[9] Fitzpatrick RE. Treatment of inflamed hypertrophic scars using intralesional 5-FU. Dermatol Surg 1999;25(3):224-32.

[10] Bijlard E, Steltenpool S, Niessen FB. Intralesional 5fluorouracil in keloid treatment: a systematic review. Acta Derm Venereol 2015;95(7):778-82.

[11] Alexandrescu D, Fabi S, Yeh LC, et al. Comparative results in treatment of keloids with intralesional 5FU/Kenalog, 5-FU/verapamil, enalapril alone, verapamil alone, and laser: a case report and review of the literature. J Drugs Dermatol 2016;15(11):1442-7.

[12] Saray Y, Güleç AT. Treatment of keloids and hypertrophic scars with Dermojet injections of bleomycin: a preliminary study. Int J Dermatol 2005;44(9):777-84.

[13] Payapvipapong K, Niumpradit N, Piriyanand C, et al. The treatment of keloids and hypertrophic scars with intralesional bleomycin in skin of color. J Cosmet Dermatol 2015;14(1):83-90.

[14] Lee RC, Ping JA. Calcium antagonists retard extracellular matrix production in connective tissue equivalent. J Surg Res 1990;49(5):463-6.

[15] Doong H, Dissanayake S, Gowrishankar TR, et al. The 1996 Lindberg award. Calcium antagonists alter cell shape and induce procollagenase synthesis in keloid and normal human dermal fibroblasts. J Burn Care Rehabil 1996;17(6 Pt 1):497-514.

[16] D'Andrea F, Brongo S, Ferraro G, et al. Prevention and treatment of keloids with intralesional verapamil. Dermatology 2002;204(1):60-2.

[17] Li Z, Jin Z. Comparative effect and safety of verapamil in keloid and hypertrophic scar treatment: a metaanalysis. Ther Clin Risk Manag 2016;12:1635-41.

[18] Danielsen PL, Rea SM, Wood FM, et al. Verapamil is less effective than triamcinolone for prevention of keloid scar recurrence after excision in a randomized controlled trial. Acta Derm Venereol 2016;96(6):774-8.

[19] Wang R, Mao Y, Zhang Z, et al. Role of verapamil in preventing and treating hypertrophic scars and keloids. Int Wound J 2016;13(4):461-8.

[20] Tilkorn H, Ernst K, Osterhaus A, et al. The protruding scars: keloids and hypertrophic diagnosis and treatment with silicon-gel-sheeting. Polim Med 1994;24(1-2):31-44.

[21] Fulton JE. Silicone gel sheeting for the prevention and management of evolving hypertrophic and keloid scars. Dermatol Surg 1995;21(11):947-51.

[22] Berman B, Flores F. Comparison of a silicone gel-filled cushion and silicon gel sheeting for the treatment of hypertrophic or keloid scars. Dermatol Surg 1999;25(6):484-6. 
[23] O'Brien L, Pandit A. Silicon gel sheeting for preventing and treating hypertrophic and keloid scars. Cochrane Database Syst Rev 2006;(1):CD003826.

[24] Rossi A, Lu R, Frey MK, et al. The use of the 300 microsecond $1064 \mathrm{~nm}$ Nd: YAG laser in the treatment of keloids. J Drugs Dermatol 2013;12(11):1256-62.

[25] Muti E, Ponzio E. Cryotherapy in the treatment of keloids. Ann Plast Surg 1983;11(3):227-32.

[26] Mende B. Treatment of keloids by cryotherapy. Z Hautkr 1987;62(18):1348, 1351-2, 1355.

[27] Jaros E, Príborský J, Klein L. Treatment of keloids and hypertrophic scars with cryotherapy. Acta Medica (Hradec Kralove) Suppl 1999;42(2):61-3.

[28] Larrabee WF, East CA, Jaffe HS, et al. Intralesional interferon gamma treatment for keloids and hypertrophic scars. Arch Otolaryngol Head Neck Surg 1990;116(10):1159-62.
[29] Doornbos JF, Stoffel TJ, Hass AC, et al. The role of kilovoltage irradiation in the treatment of keloids. Int J Radiat Oncol Biol Phys 1990;18(4):833-9.

[30] Mankowski P, Kanevsky J, Tomlinson J, et al. Optimizing radiotherapy for keloids: a meta-analysis systematic review comparing recurrence rates between different radiation modalities. Ann Plast Surg 2017;78(4):40311.

[31] Wu X, Bian D, Dou Y, et al. Asiaticoside hinders the invasive growth of keloid fibroblasts through inhibition of the GDF-9/MAPK/Smad pathway. J Biochem Mol Toxicol 2017;31(8) 